\title{
Nest-building males trade off material collection costs with territory value
}

\author{
Ida E. Bailey ${ }^{\mathrm{A}, \mathrm{E}}$, Kate V. Morgan ${ }^{\mathrm{A}}$, H. Dieter Oschadleus ${ }^{\mathrm{B}}$, Stacy L. DeRuiter ${ }^{\mathrm{C}}$, \\ Simone L. Meddle ${ }^{\mathrm{D}}$ and Susan D. Healy ${ }^{\mathrm{A}}$

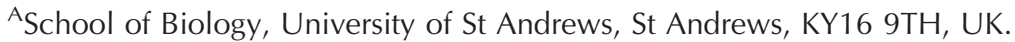 \\ ${ }^{B}$ Animal Demography Unit, Department of Biological Sciences, University of Cape Town, Cape Town, \\ South Africa. \\ ${ }^{\mathrm{C}}$ Centre for Research into Ecological and Environmental Modelling, University of St Andrews, KY16 9TH, UK. \\ DThe Roslin Institute and Royal (Dick) School of Veterinary Studies, University of Edinburgh, \\ 50 George Square, Edinburgh, EH8 9LH, UK. \\ ${ }^{\mathrm{E}}$ Corresponding author. Email: idaelizabeth@postmaster.co.uk
}

\begin{abstract}
Building a structurally robust nest is crucial for reproductive success in many birds. However, we know little about the criteria birds use to select material or where they go to collect it. Here we observed the material collection of male Cape Weavers (Ploceus capensis). Males typically selected long, strong material to build their nests and each male collected material from different locations. Males that built more nests nested in a different area of the colony and flew further to collect nest material than did males that built fewer nests. As these males that flew further to collect material had longer tails and wings and attracted more females to their territories than did males that flew shorter distances, they may have traded off the travel costs of collecting nest materials with benefits gained from holding a territory in a more 'desirable' part of the colony. Nest construction, then, appears to be a multi-dimensional task whereby birds take into account material's structural properties, material proximity to the nest site and territory quality. Males that do this effectively both attract more mates and provide structurally sound nests for their young.
\end{abstract}

Additional keywords: distance, flight costs, individuality, location, material properties, weaverbirds.

Received 25 February 2015, accepted 4 November 2015, published online 25 January 2016

\section{Introduction}

For many birds nest building is a key reproductive behaviour. A poor nest that is structurally weak may have too much/too little heat loss or be accessible to predators may thus result in the loss of its eggs or chicks (Hansell 2000). Nest building, however, appears to be costly: flight to and from collection sites, the collection of material, manipulation of nests and material manipulation in the nest are all energetically expensive (Collias and Collias 1967; Hansell 2000). For example, for a Cliff Swallow (Petrochelidon pyrrhonata) to collect the $600 \mathrm{~g}$ of mud necessary to complete a nest, they must make around 1400 material collection trips. Total energy expenditure for the construction of the resulting nest has been estimated at $122 \mathrm{KJ}$, based on $20 \mathrm{~s}$ flights, $10 \mathrm{~s}$ spent collecting mud and $30 \mathrm{~s}$ spent arranging it at the nest (Withers 1977).

Flight costs are proportional to the time spent in flight, which in turn is directly related to the distance flown (Nudds and Bryant 2000). Therefore, the further birds fly to collect material the more costly the trip will be. In one colony of Village Weavers (Ploceus cucullatus) nesting $\sim 40 \mathrm{~m}$ from their source of nestbuilding material, birds flew an average of 325 round trips (a total of $26 \mathrm{~km}$ ) to gather and bring back material for just the outer shell of a single nest and approximately seven nests were built for every successful brood raised in the colony (Collias and Collias 1967).

Further evidence that nest construction is energetically costly comes indirectly from the production of larger fledglings by Pied Flycatchers (Ficedula hypoleuca) that were provided with a ready-built nest at the start of the nest-building relative to control birds who built their own nests (Moreno et al. 2010; Mainwaring and Hartley 2013). Females provided with nests collected less nest material, completed their nests in a shorter period, spent a greater proportion of time incubating their eggs and initially provisioned their offspring at a higher rate than did females that had to build an entirely new nest.

Time spent away from the territory may also be costly. For species that use their nests as part of their signalling displays to females, absence from the territory might not only provide opportunity for neighbours to steal material (Atwood 1979; Nores and Nores 1994; Hansell 2000; Prochazka et al. 2007) but the longer the absence, the more likely it is that a neighbour may attract the next female prospecting for a nest. For example, male Seychelles Warblers (Acrocephalus sehellensis) that are distracted from guarding their mate by the addition of a fake egg 
to the nest (which they then incubate) suffer a higher rate of extra-pair paternity than do males that continue to guard their mate during her fertile period (Komdeur et al. 1999).

When unable to steal or re-use nest material a nest builder's decisions about where to collect building materials may depend on several factors including the prevalence of useful materials in the environment, predation risk, variation in material quality, the distance it needs to travel to collect appropriate material and the time taken to collect that material. Depending on the relative costs of each of these factors birds may trade off one or more of the factors associated with material collection with another. For example, Marsh Harriers (Circus aeruginosus) trade off between minimising material collection costs and ensuring the nest's structural integrity quality by using less preferred materials such as cattail (Typha latifolia) more often when preferred materials such as Common Reed (Phragmites australis) are further away (Stanevičlus and Baleviclus 2005).

To our knowledge, quantification of the costs to individuals of collecting material coupled with data on other building decisions, such as where to build the nest and how much time to invest in building, has been rarely attempted in any substantial way. Here we used a colony of nest-building Cape Weaver (Ploceus capensis) males to identify the locations to which the builders flew to collect nest material and the material they collected in order to assess some of the costs of building.

The Cape Weaver is colonial and polygynous, attracting several females per male in a breeding season by building multiple nests consecutively. In related species the number of females a male attracts is roughly proportional to the number of nests he builds (Friedl and Klump 1999). The breeding season of the Cape Weaver is from June to December in the winterrainfall region of the Western Cape, South Africa. The male typically leaves all the incubation and care of chicks to the females (Hockey et al. 2005).

Using this colony of nest-building Cape Weavers, we had three main aims, which were to: (1) establish whether males that built nests in the same colony differed in the locations from which they collected nest material; (2) uncover the criteria that birds used to decide what material to collect and where to collect it (e.g. material: location, abundance and physical properties); (3) determine the costs (in time and distance flown) associated with nest building plus the benefits gained by males from their nest-buildings effort with regard to the number of females that chose to occupy those nests.

\section{Methods}

\section{Site and observational data}

We made our observations at Die Oog Bird Sanctuary, Lakewood Avenue, Bergvliet ( $\left.34^{\circ} 2^{\prime} 53.8^{\prime \prime} \mathrm{S}, 18^{\circ} 26^{\prime} 48.9^{\prime \prime} \mathrm{E}\right)$, a small public park in suburban Cape Town, South Africa. The park consists of a lake surrounded by short grassland with an adjacent marshy meadow (see Fig. S1 in the Supplementary material, available online). The Cape Weavers we observed built their nests in a linear colony running south to north in Populus trees overhanging the water between the lake to the east and the meadow to the west. Around half of the territorial males were mist netted and colour ringed for individual identification between July-September 2013, before the collection of observational data. As all the males were strongly territorial and rarely landed in a territory other than their own the other males could be reliably identified by the position of their territory in the colony.

To determine where birds went to collect material and to identify the type and number of pieces of material collected, one observer was located beside the colony from where they could watch each focal male weaverbird collecting material from around the banks of the lake. As the meadow was not visible to the first observer, a second observer was located at vantage point overlooking the meadow from which they could observe focal birds collecting material from the meadow or road embankment beyond.

We observed bird behaviour between 8.30 a.m. (about two hours after sunrise) and 5 p.m. (about an hour before sunset) over an eight-week period (October-November, 2013). We began observing nests from as early in the nest construction process as possible (usually from the first piece collected) until the male either stopped building or started adding ceiling material such as leaves to the inside of the roof. This indicated that the main outer structure of the nest was complete. If a male did not complete the outer-shell of his nest within a day, we observed building of the same nest the following day. In total, we observed nest building by 12 individual males and observed 7 of these males building 2 different nests. The position (distance north-south and east-west) in the colony of all the nests was measured by pacing from a tree at the south end of the colony and nest height was estimated by eye. We also observed which nests became occupied by females.

We recorded the number and duration hh:mm:ss (using a digital watch) of behaviours performed by the focal male including: displaying, weaving, chasing intruders, fighting, preening, perching, singing, removing material from a nest, removing leaves from branches, chasing females, feeding chicks and absence from the territory (for definitions, see Supplementary material).

We also estimated by eye the length of each piece of material that males brought back to the nest as being short $(<\sim 15 \mathrm{~cm}$ : shorter than the length of the bird), medium $(\sim 15-30 \mathrm{~cm}$ : as long/twice as long as the bird) or long (> 30 cm: over twice as long as the bird). Measurement using a ruler would not have been possible without seriously disrupting the birds' behaviour. Where possible, we also recorded material type e.g. grass, sedge, leaves.

All observations were conducted in accordance with ethical review procedures at the University of St Andrews and the UK Animals (Scientific Procedures) Act 1986 and associated guidelines.

\section{Material availability and structural properties}

We estimated the availability of different species of potential building material across the meadow by eye using a $1.2 \times 1.2 \mathrm{~m}$ grid system and visually estimated the proportion of different species in each grid square. We made our visual observations from an elevated position from the sides of the meadow only, both to prevent disturbing other nesting birds and because much of it was inaccessible swamp. 
To allow comparison of the structural properties of available building materials, we collected 25 leaves of the species of plants that birds appeared to use for building the outer-shell of their nests and 10 leaves of every other plant species growing in the meadow that had long narrow leaves, a leaf form favoured by weaverbirds (Collias and Collias 1964a). We took samples of 8 species: 4 grasses, 3 sedges and 1 reed and, where possible, plant species were identified (see Table S1). From these 8 species, we took whole leaves either from ground level or adjacent to the main stem (depending on plants growth pattern, some species only had leaves originating from ground level), choosing leaves at random. We collected leaves from several locations across the study site to increase the representativeness of samples for that species to avoid within-plant replicates. We stored samples in plastic bags in a Styrofoam cool box with ice packs to prevent dehydration. We then measured the length, width and strength of 5 randomly selected samples for each species and collection site within 5 hours of collection.

We measured leaf width at the widest point and leaf length using a measuring tape. To measure strength, we clamped $10 \mathrm{~cm}$ lengths of the leaves taken from the basal end between two rubber-lined pieces of wood $(5 \times 2 \mathrm{~cm})$ such that two centimetres of the leaf was inside the clamp. To prevent the leaf sample from slipping out, the clamp was tightened using a bolt running through the centre of both pieces of wood and wing nut. We then hung the clamp from a $5 \mathrm{~kg}$ pull balance and holding the lowest $2 \mathrm{~cm}$ of the piece of material pulled on it until it broke. If the material pulled over $5 \mathrm{~kg}$ then we tore it along its length to give a narrower strip, measured the new width and repeated the strength test. This material breaking procedure was recorded using a digital video camera. The weight reading on the scale $(\mathrm{g})$ when the material broke was determined from low speed video footage. The breaking strength was calculated as the weight reading on the scale (g) when the material broke / the materials width $(\mathrm{mm})$.

\section{Morphological data}

For colour-ringed males morphological measures including body mass, wing length and tail length were recorded at the time of ringing up to three months before our building observations. Body mass may have changed over the intervening period but wing and tail lengths would have remained constant as moulting in this species occurs after the conclusion of the breeding season (Craig et al. 2001).

\section{Data analysis}

Unless otherwise stated, all data were analysed using the statistics packages JMP transforming the data for normality if residuals were not normally distributed.

\section{Nest material properties}

To compare the physical properties of different building materials (plant leaves) we used linear regression models with plant species and condition (fresh or dried) as main effects. Where there were differences among species in their physical properties we used Post-hoc Tukey-Kramer honest significant difference (HSD) tests to investigate this variation further.

\section{Length of material added to the nest}

First, we calculated the total number of each piece of material of each of three lengths (short, medium and long) that each bird had brought to its nests. We then analysed these data using a linear mixed model with bird as a random factor and material length as a main effect to investigate if birds brought more of some lengths of materials than others to their nests. We then used Post-hoc Tukey-Kramer HSD tests to investigate this variation further.

\section{Collection site choice and material availability}

Using a linear regression model, we looked to see whether the number of pieces of long material of a given length collected in each square of the meadow was related to the proportion of that square occupied by each of the three main building materials (grass, sedge 1 and sedge 2) or to the distance of the square from the colony (i.e. the number of pieces of long material birds collected in each square $\sim$ proportion of the square covered by grass + proportion of the square covered by sedge $1+$ proportion of the square covered by sedge $2+$ distance of the square from the colony). Similar analyses were not meaningful for short and medium lengths of material as short and medium materials were collected from too few squares ( 25 and 33 of 112 squares respectively relative to 55 squares for long material).

\section{Individuality of material collection sites}

We analysed the spatial arrangement of nest material collection sites (statistics package R (R Core Team 2014) using the package spatstat (Baddeley and Turner 2005) to determine whether males differed from each other in their material collection locations. This statistics package requires a point pattern matrix where no two points lie on top of each other and as in our data multiple collection points were quite often in the same place, we used the jitter function in $\mathrm{R}$ statistical computing software to add a small amount of noise (random samples from a uniform distribution with minimum $-1 \mathrm{~cm}$ and maximum $1 \mathrm{~cm}$ ) to the coordinates of each collection point so that each observation was associated with a unique location.

To determine whether individual males differed in where they collected nest material we calculated the degree of clustering of each bird's material collection points. Specifically, we used Ripley's K function (evaluated at $1 \mathrm{~m}$ radius), which measures how the number of collection sites within $1 \mathrm{~m}$ of other sites of the same type compares with the number expected based on the overall density of points of that type (Diggle 2003). We tested whether collection site location was independent of bird identity using a randomisation test with median $\mathrm{K}$ function across all birds as the test statistic (custom script written in $\mathrm{R}$ statistical software with $n=10000$ iterations). To exclude the possibility that any differences were due to the stage of nest-building, we analysed only the collection of long and medium length material.

\section{Attributes of males' territories, collection sites,} behaviours and female nest use

Often in colonially breeding species the position of a male's territory in the colony influences his breeding success (e.g. Carey 1991). Therefore, using linear regression models, we 
examined the statistical relationships among the location of a male's territory in the linear colony, which ran south to north, with where he went to collect material, the number of nests he had, his morphology and the distance he travelled to collect material. To do this, we ranked the position of the males' territories in the colony south to north (territory 1 to 12 with 1 being the most southerly territory and 12 the most northerly) and did the same for the mean of their material collection locations. However, the distribution of collection locations for some birds, particularly those locations situated at the edge of the colony, was bi-modal, due to these males collecting material around the banks of the lake as well as from the main meadow. Therefore, we analysed data only for the collection locations within the main meadow. In addition, again using linear regression models, we examined the statistical relationships between the number of nests each male had, the time he spent on his territory, the time he spent weaving, the number of pieces of material he collected per trip and the number of females that nested in his territory. Analysis of the number of pieces of material collected per trip was limited to data for long and medium lengths of material as for short material, such as a bunch of leaves, it was almost impossible to tell how many items the bird was carrying. All factors were compared as means for each male.

Additionally, as nest height over the water may affect the risk of the nest being flooded or vulnerable to predation, we also examined female preference for nests built at different heights. To do this we compared the average height of all nests in the colony to the heights of nests occupied by females using a $t$-test.

\section{Results}

\section{Material type}

The birds used two species of sedge, sedge1 Bolboschoenus maritimus and sedge 2 Cyperus textilis, one species of reed, Phragmites australis, and three species of grass: grass 1, a European invasive species, grass 2, another unknown species and grass 3, Pennisetum clandestinum, with which to build their nests (Table S1). Only the sedges and the grasses were available in the main meadow and these occurred in fairly distinct areas: sedge 1 was the most common material in the area that the birds visited most frequently during material collection while the reed grew only around the banks of the lake (of the 59 squares in the meadow from which birds collected any material, sedge 1 occurred in 31 squares, grass of any sort occurred in 21 squares and sedge 2 in only three squares). It was only possible to identify the type of material (plant species) birds collected for $\sim 50 \%$ of pieces of material brought to the nest. Most of the short material identified was grass or sedge 2, most of the medium material identified was grass or reed 1, and most of the long material identified was sedge 1 (Table S2).

\section{Physical attributes of the materials available for building \\ Material strength}

The plants available varied in the strength $(\mathrm{g} / \mathrm{mm}$ width) of their leaves (Adjusted $\mathrm{R}^{2}=0.69, \mathrm{~F}_{7,81}=30.48, P<0.001$; Fig. S2(a)). Sedge 1 Bolboschoenus maritimus was the strongest material ( $\mathrm{g} / \mathrm{mm}$ width) but was not significantly stronger than reed 1 Phragmites australis (Post-hoc Tukey-Kramer HSD tests, $\alpha=0.05$ ). Reed 1 , sedges 2 and 3 Cyperus textilis and Carex clavata and grass 3 Lolium perenne were the next strongest materials and were similar in strength to one another. The grasses were the weakest of the materials we tested and all were similar in strength (Fig. S2(a)).

\section{Material length}

The available plant species varied in the length of their leaves (Adjusted $\mathrm{R}^{2}=0.97, \mathrm{~F}_{7,81}=235.84, P<0.001$ ). Material length, longest to shortest: sedge $3>$ sedge $1>$ reed $1=$ grass $3=$ grass 1 ; sedge $2=$ grass $1=$ grass 2 and grass 4 (Fig. S2(b)).

\section{Nest building}

\section{Materials brought to the nest}

We observed males building each nest for 2.1-10.5 h (Mean $=4.6 \pm 0.4 \mathrm{~h} \mathrm{SE}$ ). The total number of pieces they added to the nests during observation periods varied as did the rate at which they added material (Table S3). Males also varied in the number and rate of addition of pieces of different lengths of material they brought to the nest (Table S3). Males brought more pieces of long than of short or medium material to their nests (Adjusted $\mathrm{R}^{2}=0.77, \mathrm{~F}_{2,22}=16.90, P<0.001$ ) and a similar number of pieces of short and medium pieces.

\section{Collection site choice and material availability}

Males collected more long material from those squares that contained a higher proportion of sedge 1 than from squares with a low proportion of sedge 1 (Adjusted $\mathrm{R}^{2}=0.58$, $\left.\mathrm{F}_{1,104}=43.03, P<0.001\right)$. They also collected more long material from squares that were closer to rather than further from the colony $\left(\mathrm{F}_{1,104}=65.17, P<0.001\right)$. The proportion of grass or sedge 2 in squares was not correlated with birds' collection of long material (grass: $\mathrm{F}_{1,104}=0.05, P=0.829$; sedge 2: $\left.\mathrm{F}_{1,104}=0.04, P=0.847\right)$.

\section{Variation in nest material collection locations}

We tested whether individual males differed in the locations to which they went to collect material. The analysis showed that although each male's collection locations overlapped, males differed in the locations from which they collected material $(P<0.001$; Fig. 1).

\section{Location of nests relative to nest material collection sites}

We examined whether the position of a male's territory in the colony was related to where he collected material. Males with territories further south also collected material from locations that were further south (Adjusted $\mathrm{R}^{2}=0.37, \mathrm{~F}_{1,10}=6.05$, $P=0.033$; Fig. $2 a$ ). The position of a male's territory south did not affect how far to the west he collected material (Adjusted $\left.\mathrm{R}^{2}=-0.02, \mathrm{~F}_{1,10}=0.76, P=0.405\right)$.

\section{Distance travelled for material}

Birds that built nests further south in the colony travelled further to collect nest material than did those birds nest building 


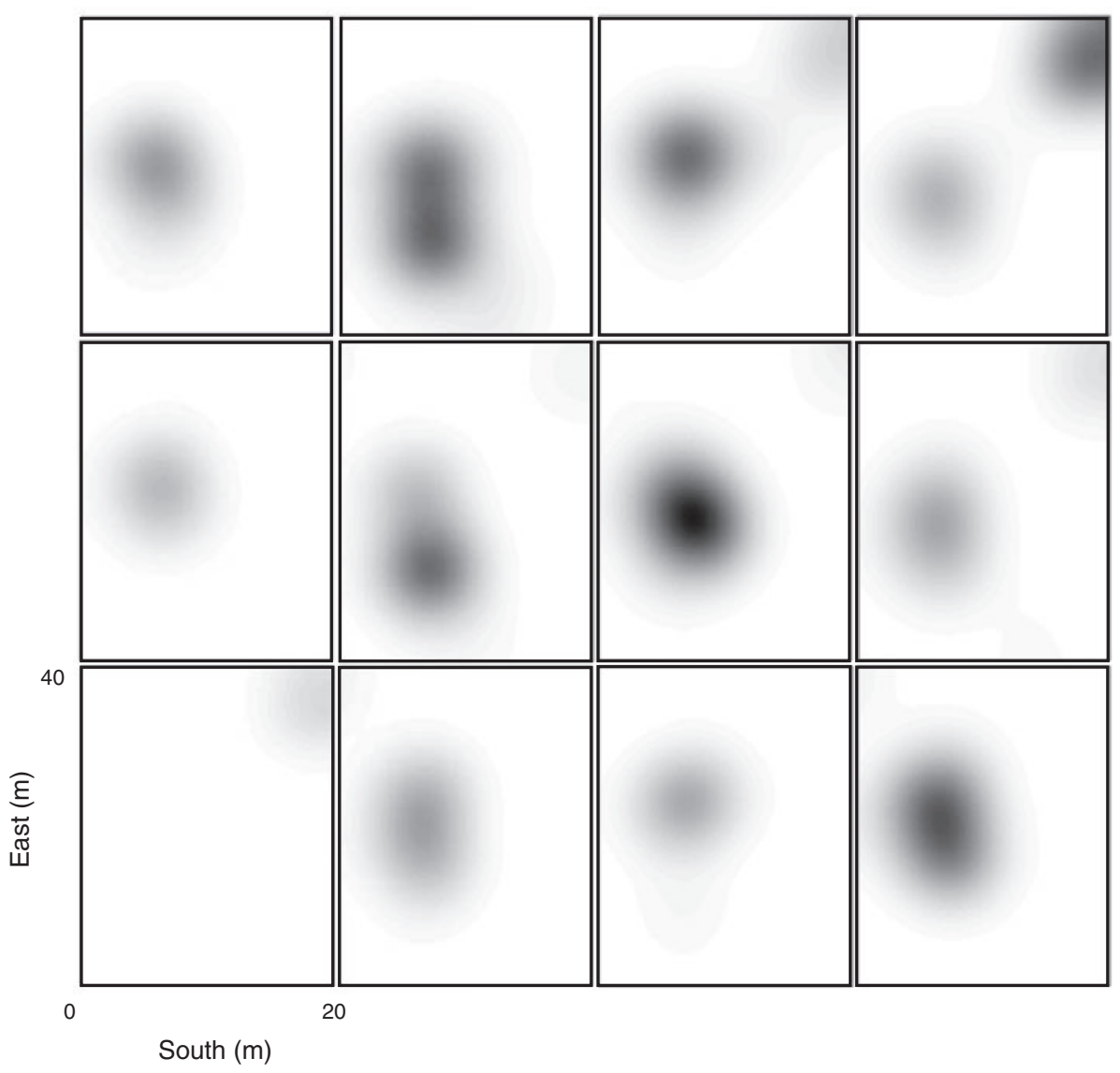

Fig. 1. The area covered by each panel in the above figure represents the meadow and the areas of the lake bank the male Cape Weavers used for material collection. Individual panels show the material collection locations of a single bird (specifically, each panel shows a kernel smoothed intensity function (Diggle 1985), based on the data for each bird's material collection site). The intensity of the shading scales with the number of times material was collected from a given area. The axes represent the distances south and east from the top north-west point of our observation area.

further to the north in the colony (Adjusted $\mathrm{R}^{2}=0.29$, $\mathrm{F}_{1,10}=5.47, P=0.041$; Fig. $2 b$ ). Those males that flew further to collect material also took more time to complete a round trip to collect nest material than did males that flew less far (Adjusted $\left.\mathrm{R}^{2}=0.40, \mathrm{~F}_{1,10}=8.23, P=0.017\right)$.

\section{Number of nests built}

The number of nests a male built was related to the location of his territory in the colony: the further south (Fig. S1), the more nests a male built (Adjusted $\mathrm{R}^{2}=0.44, \mathrm{~F}_{1,13}=12.11$, $P=0.004$; Fig. 2c). Furthermore, males with longer wings and tails built more nests than did males with shorter wings and tails (Wings, Adjusted $\mathrm{R}^{2}=0.43, \mathrm{~F}_{1,6}=6.23, P=0.047$; Tails, Adjusted $\mathrm{R}^{2}=0.55, \mathrm{~F}_{1,6}=9.49, P=0.022$ ). Males that built more nests were not heavier than were the males that built fewer nests (Adjusted $\mathrm{R}^{2}=-0.12, \mathrm{~F}_{1,6}=0.23, P=0.644$ ).

\section{Behaviour}

Of the birds we observed building, males that built more nests also spent a greater proportion of their time weaving
(Adjusted $\mathrm{R}^{2}=0.33, \mathrm{~F}_{1,10}=6.48, P=0.029$ ), a smaller proportion of their time away from their territory (Adjusted $\mathrm{R}^{2}=0.32$, $\left.\mathrm{F}_{1,10}=6.22, P=0.031\right)$, and collected more pieces of material per trip (Adjusted $\mathrm{R}^{2}=0.34, \mathrm{~F}_{1,10}=6.16, P=0.035$ ) than did birds that built fewer nests. There was no relationship between the number of nests males built and the proportion of their time they spent displaying (Adjusted $\mathrm{R}^{2}=0.03, \quad \mathrm{~F}_{1,10}=1.35$, $P=0.272)$.

\section{Mating success}

Of the nine females that nested in the colony during the observation period, more nested in the territories of males that built more nests than nested in the territories of males who built fewer nests (Adjusted $\mathrm{R}^{2}=0.27, \mathrm{~F}_{1,13}=6.32, P=0.026$ ). Females also chose nests that were closer to the water than the average nest (Mean height over water: All nests $=142.23 \pm 7.04$ $\mathrm{cm}$, Nests with females $=85.56 \pm 7.47 \mathrm{~cm} \mathrm{SE}$; $t$-test: $\mathrm{t}_{8}=-7.57$, $P<0.001)$. Males whose nests were on average closer to the water, however, did not necessarily have more females nesting in their territories than males whose nests were higher up (Adjusted $\mathrm{R}^{2}=0.13, \mathrm{~F}_{1,13}=3.07, P=0.103$ ). 

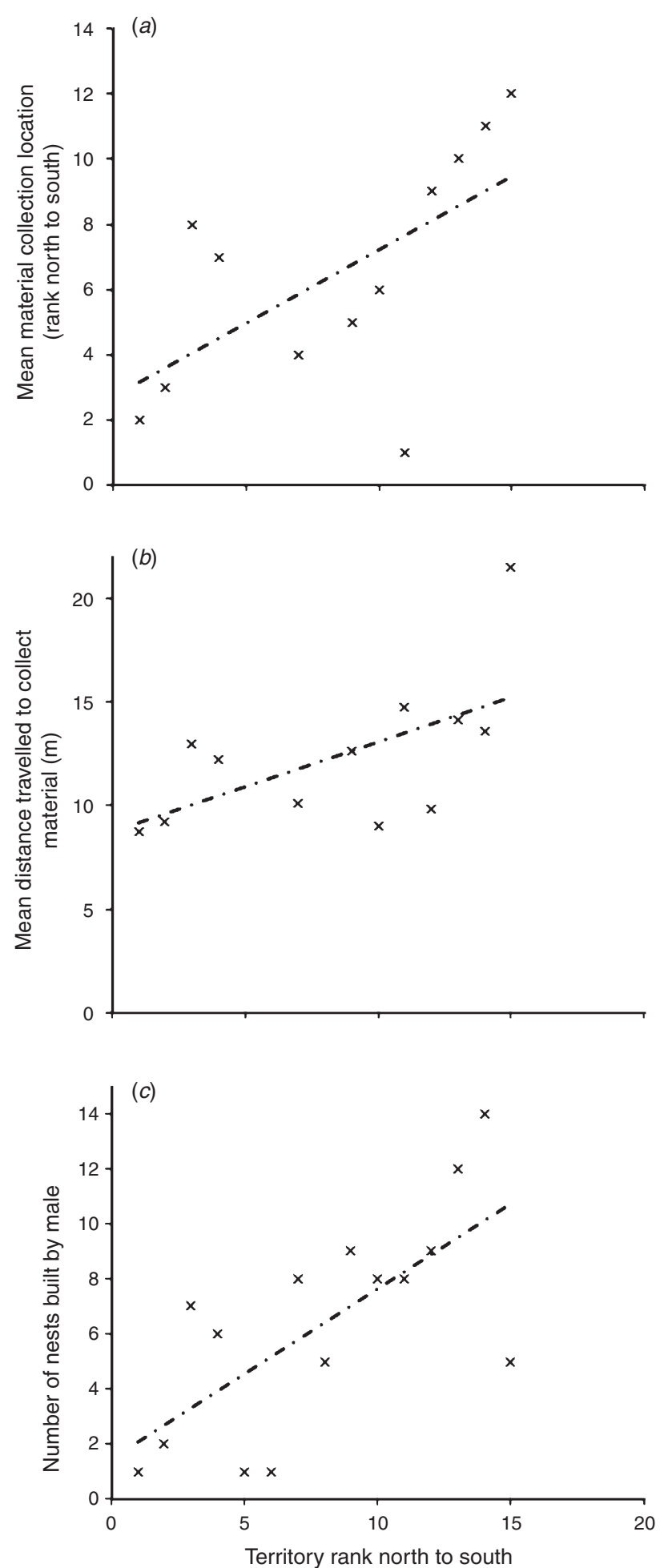

Fig. 2. (a) Male Cape Weavers with territories further south collected nest material from locations further south in the meadow than did males with nesting territories less far south $(n=12)$; $(b)$ Males with territories further south travelled further to collect nest material than did males nesting less far south ( $n=12)$; (c) Male with territories further south built more nests than did males nesting less south $(n=15)$. In all panels, the data for each male is plotted across and the best-fit linear regression line is a dash-dotted line.
There was no relationship between the number of females nesting in a territory and the proportion of time males spent displaying (Adjusted $\mathrm{R}^{2}=-0.9, \mathrm{~F}_{1,10}=0.05, P=0.821$ ), weaving (Adjusted $\mathrm{R}^{2}=-0.05, \mathrm{~F}_{1,10}=0.41, P=0.538$ ), or away from their territory (Adjusted $\mathrm{R}^{2}=14, \mathrm{~F}_{1,10}=2.78, P=0.126$ ).

\section{Discussion}

Individual male weaverbirds differed in the locations at which they collected nest material but those males that flew further to collect material built more nests than did those males that flew shorter distances. These more productive males also spent more, not less, time on their territories, collected more pieces of material per trip and were more likely to attract females to their nests.

Energy expenditure during flight is related to the time spent in flight and thus the distance flown (Nudds and Bryant 2000). Males that flew further to collect material would, therefore, have expended more energy on material collection per nest than did males that flew less far. Perhaps surprisingly, however, the more productive males also spent more time on their territories than did the less productive males. This could mean that the more productive males were more efficient in their building and collection of materials than were the less productive males by, for example, collecting the same amount of material in less time or building a nest with less material. Of these two possibilities, our data suggest that they were certainly more efficient in their material collection as they collected more pieces of material per round trip than did males who built fewer nests. An alternative explanation is that more productive males sacrificed time they might have spent away from their territory for some other reason, such as for foraging. Male Grey-headed Flying-foxes (Pteropus poliocephalus) appear to sacrifice foraging time in favour of remaining on a territory, losing up to $20 \%$ of their body mass during the breeding season through territory defence and lost foraging opportunities (Welbergen 2011). Male Black Grouse (Tetrao tetrix) also lose mass while defending breeding territories on leks: more successful males, typically those with higher lek attendance, lose more mass than do less successful males at the lek periphery (Rintamaki et al. 2001; Lebigre et al. 2013). We do not have, however, have body mass data from the weavers taken sufficiently close to the time of observation to confirm that this is, indeed, what the more productive males did.

Male Cape Weavers that built more nests were more likely to attract females as are Long-billed Marsh Wrens (Telmatodytes palustris) (Verner and Engelsen 1970), Eurasian Wrens (Troglodytes troglodytes) (Verner and Engelsen 1970; Garson 1979) and various weavers including: Southern Red Bishop (Euplectes orix) (Friedl and Klump 2000; Lawes et al. 2002; Metz et al. 2007; Metz et al. 2009), and Village Weaver (McAlary et al. 1984). The costs of spending more time on the territory, therefore, appears to be counterbalanced by the benefit of females being more likely to choose a nest built by a male who has more nests in his territory. Territory attendance is directly linked with mating success in other polygynous species including Black Grouse and Galapagos Sea Lions, (Zalophus wollebaeki) (Rintamaki et al. 2001; Meise et al. 2014). In our study the effect might have been mediated by two factors: 
(1) building more nests takes more time and so males are on their territories for longer; (2) building males can also display either themselves or their nests to any unmated females visiting the colony, visits they may have missed if they had not been on their territories.

Males that spend more time on their territories building nests may, then, have extra opportunities to display to and attract the attention of unmated females whenever they happen to visit the colony than do less attentive males. Building males constantly interrupted their building to display to females, which would support this possibility. Although we did not see an effect of the time males spent displaying on the probability of females nesting in their territories, it is possible that display quality and content are more important to female choice than is the amount of time males spend displaying.

It is not clear what the advantage was either to males of building in a location at the southern end of the colony or to females of choosing nests located in this part of the colony. That there was some advantage was supported by the males from these territories being prepared to fly further to collect materials for building. Nesting Razorbills (Alca torca) will also trade off flight costs, albeit with prey patch quality rather than nest-site desirability, as they fly further to better food sources (Shoji et al. 2014). That it was costly for male weavers to fly to the locations at which they collected the materials is supported by the observation that males collect material from the closest locations to their nest with suitable materials.

In contrast to nest choice in female Baya Weavers (Ploceus philippinus), which prefer to nest high in trees to lower risk of predation from terrestrial predators such as snakes and rodents (Quader 2006), in the present study Cape Weaver females preferred nests that were relatively close to the water. Most of the Baya Weaver colonies were over dry land rather than over water (37 out of 43), whereas in the current study the Cape Weavers were nesting over water. It seems possible that predation risk for the Cape Weavers increased rather than decreased with height above water as predators such as Eastern Gray Squirrels (Sciurus carolinensis) (Newson et al. 2010), or large raptors such as African Harrier-hawk (Polyboroides typus) are more at risk of falling in the water if they prey on low hanging nests (Smeenk and Smeenkenserink 1983; Tweddle and Tweddle 1984; Ginn 1991; Newson et al. 2010). Additionally, if wind speed is lower closer to the water, building the nest lower would be advantageous as strong winds can snap branches supporting nests and cause eggs and chick to fall from nests as the nests are blown around (Collias and Collias $1964 b)$.

Male weaverbirds largely chose material that was both long and strong to build the outer shell of their nests but they added an increasing proportion of shorter, weaker material as their nest building progressed. A preference for longer material for the main nest structure seems fairly typical for Ploceus weavers. It appears that they develop this preference as juveniles and continue to select longer materials for nest weaving as adults (Collias and Collias 1962; Collias and Collias 1964a). This current study is to our knowledge, the first evidence that weaverbirds prefer stronger over weaker building materials and may trade off material length and material strength, choosing materials that were longer and stronger rather than materials that were just long or strong. It has been suggested that stronger materials are used by birds building in more exposed than in more sheltered locations, although there are, as yet, no data to support these claims (Crook 1963). More widely, other species of birds also show preferences for different material properties when nest-building. For example Varied Tits (Parus varius) prefer mosses with certain biotic traits and Helmeted Honeyeaters (Lichenostomus melanops cassidix) prefer cribellate over ecribellate spider silk (Du et al. 2010; Low et al. 2013). In the case of Zebra Finches (Taeniopygia guttata), a learnt preference for stiffer over more flexible string appeared to be related to the material's efficacy for building (Bailey et al. 2014). Together this evidence suggests that decisions over choice of nest material are based on multiple components, including material structural properties, efficacy for building in a given situation plus proximity to the nest site.

\section{Acknowledgements}

This work was supported by the BBSRC (BB/I019502/1 to SDH and SLM) and Roslin Institute Strategic Grant funding from the BBSRC (SLM). We thank Sue and Barry Schultz for their help with the design and manufacture of the clamp used in material strength tests. We thank Dalton Gibbs for his assistance in identifying plant species, and the editors and two anonymous reviewers for their helpful comments on earlier versions of this manuscript.

\section{References}

Atwood, J. L. (1979). Robbery of nesting materials by the Calliope hummingbird Stellula calliope. Western Birds 10, 43-44.

Baddeley, A., and Turner, R. (2005). spatstat: An R package for analyzing spatial point pattern. Journal of Statistical Software 12, 1-42. doi:10.186 37/jss.v012.106

Bailey, I. E., Morgan, K. V., Bertin, M., Meddle, S. L., and Healy, S. D. (2014). Physical cognition: birds learn the structural efficacy of nest material. Proceedings of the Royal Society B: Biological Sciences 281, 20133225. doi:10.1098/rspb.2013.3225

Carey, P. W. (1991). Resources-defence polygyny and male territory quality in the New Zealand fur seal. Ethology 88, 63-79. doi:10.1111/j.14390310.1991.tb00263.x

Collias, N. E., and Collias, E. C. (1962). An experimental study of the mechanisms of nest building in a weaverbird. The Auk 79, 568-595. doi: $10.2307 / 4082640$

Collias, E. C., and Collias, N. E. (1964a). The development of nest-building behavior in a weaverbird. The Auk 81, 42-52. doi:10.2307/4082609

Collias, N. E., and Collias, E. C. (1964b). Evolution of nest-building in the weaverbirds (Ploceidae). University of California Press, Berkeley.

Collias, N. E., and Collias, E. C. (1967). A quantitative analysis of breeding behaviour in the African village weaver. The Auk 84, 396-411. doi:10.23 $07 / 4083089$

Craig, A. J. F. K., Hulley, P. E., Whittington-Jones, C. A., and Bonnevie, B. T. (2001). Flying times and flight feathers: patterns of molt in sympatric seedeaters. The Ostrich 15(Supplement), 66-70.

Crook, J. H. (1963). A comparative analysis of nest structure in the weaver birds (Ploceinae). The Ibis 105, 238-262. doi:10.1111/j.1474-919X.19 63.tb02498.x

Diggle, P. J. (1985). Kernel method for smoothing point process data. Journal of the Royal Statistical Society. Series C, Applied Statistics 34, 138-147.

Diggle, P. J. 2003. Statistical Analysis of Spatial Point Patterns. (Edward Arnold, London). 
Du, Y., Huo, Y.-P., Wan, D.-M., Sun, J., Lue, Y.-T., and Cao, J. (2010). Moss selection as nest materials by Parus varius. Chinese Journal of Zoology 45, 144-149.

Friedl, T. W. P., and Klump, G. M. (1999). Determinants of male mating success in the red bishop (Euplectes orix). Behavioral Ecology and Sociobiology 46, 387-399. doi:10.1007/s002650050634

Friedl, T. W. P., and Klump, G. M. (2000). Nest and mate choice in the red bishop (Euplectes orix): female settlement rules. Behavioral Ecology 11, 378-386. doi:10.1093/beheco/11.4.378

Garson, P. J. (1979). Female choice in village weaverbirds. Animal Behaviour 27, 309-310. doi:10.1016/0003-3472(79)90151-9

Ginn, P. J. (1991). Predation of weaverbirds nests by birds of prey. The Honeyguide 37, 18-19.

Hansell, M. (2000). Bird Nests and Construction Behaviour. (Cambridge University Press, Cambridge).

Hockey, P. A. R., Dean, W. R. J., and Ryan, P. G. (2005). Roberts - Birds of Southern Africa, 7th ed. (The Trustees of the John Voelcker Bird Book Fund, Cape Town).

Komdeur, J., Kraaijeveld-Smith, F., Kraaijeveld, K., and Edelaar, P. (1999). Explicit experimental evidence for the role of mate guarding in minimising loss of paternity in the Seychelles warbler. Proceedings. Biological Sciences 266, 2075-2081. doi:10.1098/rspb.1999.0890

Lawes, M., Slotow, R., and Andersson, S. (2002). Male nest building but not display behaviour directly influence mating success in the polygynous red bishop, Euplectes orix. The Ostrich 73, 87-91. doi:10.1080/00 306525.2002.11446735

Lebigre, C., Alatalo, R. V., and Siitari, H. (2013). Physiological costs enforce the honesty of lek display in the black grouse (Tetrao tetrix). Oecologia 172, 983-993. doi:10.1007/s00442-012-2548-9

Low, P. A., Angus, W. J., Wagner, A., Wilkin, D., Shiels, M., Dockerill, R., and Hochuli, D. F. (2013). Use of spider silk for nest building by the Regent Honeyeater Anthochaera phrygia and the Helmeted Honeyeater Lichenostomus melanops cassidix. Australian Zoologist 36, 349-354. doi:10.7882/AZ.2013.001

Mainwaring, M. C., and Hartley, I. R. (2013). The energetic costs of nest building in birds. Avian Biology Research 6, 12-17. doi:10.3184/175 815512 X13528994072997

McAlary, F., Jacobs, C., Fujimoto, J., and Collias, N. (1984). The relative importance of the male and the territory in nest selection by the female African village weaverbird. American Zoologist 24, A53.

Meise, K., Piedrahita, P., Kruger, O., and Trillmich, F. (2014). Being on time: size-dependent attendance patterns affect male reproductive success. Animal Behaviour 93, 77-86. doi:10.1016/j.anbehav.2014.04.019

Metz, M., Geberzahn, N., Hansen, L. H., Klump, G. M., and Friedl, T. W. P. (2007). Effects of behavioural time budgets and nest-building efficiency on male reproductive performance in red bishop (Euplectes orix). Journal für Ornithologie 148, 145-155. doi:10.1007/s10336-0060111-3
Metz, M., Klump, G. M., and Friedl, W. P. (2009). Male nest-building behaviour and mating success in the red bishop (Euplectes orix). Behaviour 146, 771-794. doi:10.1163/156853909X446208

Moreno, J., Lobato, E., Gonzalez-Braojos, S., and Ruiz-de Castaneda, R. (2010). Nest construction costs affect nestling growth: a field experiment in a cavity-nesting passerine. Acta Ornithologica 45, 139-145. doi:10. 3161/000164510X551291

Newson, S. E., Leech, D. I., Hewson, C. M., Crick, H. Q. P., and Grice, P. V. (2010). Potential impact of grey squirrels Sciurus carolinensis on woodland bird populations in England. Journal für Ornithologie 151, 211-218. doi:10.1007/s10336-009-0445-8

Nores, A. I., and Nores, M. (1994). Nest-building and nesting-behavior of the brown cacholote. The Wilson Bulletin 106, 106-120.

Nudds, R. L., and Bryant, D. M. (2000). The energetic costs of short flights in birds. The Journal of Experimental Biology 203, 1561-1572.

Prochazka, P., Pozagayova, M., and Honza, M. (2007). An interesting case of interspecific stealing of nest material. Sluka 4, 91-94.

Quader, S. (2006). What makes a good nest? Benefits of nest choice to female Baya Weaver (Ploceus philippinus). The Auk 123, 475-486. doi:10.1642/0004-8038(2006)123[475:WMAGNB]2.0.CO;2

R Core Team 2014. R: A Language and Environment for statistical Computing. (R Foundation for Statistical Computing, Vienna, Austria).

Rintamaki, P. T., Hoglund, J., Alatalo, R. V., and Lundberg, A. (2001). Correlates of male mating success on black grouse (Tetrao tetrix $L$.) leks. Annales Zoologici Fennici 38, 99-109.

Shoji, A., Owen, E., Bolton, M., Dean, B., Kirk, H., Fayet, A., Boyle, D., Freeman, R., Perrins, C., Aris-Brosou, S., and Guilford, T. (2014). Flexible foraging strategies in a diving seabird with high flight cost. Marine Biology 161, 2121-2129. doi:10.1007/s00227-014-2492-9

Smeenk, C., and Smeenkenserink, N. (1983). Observations on the harrier hawk Polyborodies typus in Nigeria, with comparative notes on the neotropical crane hawk Geranospiza caerulescens. Ardea 71, 133-143.

Stanevičlus, V., and Baleviclus, A. (2005). Factors influencing nest material selection in marsh harrier (Circus aeruginosus). Acta Zoologica Lituanica 15, 21-30. doi:10.1080/13921657.2005.10512605

Tweddle, D., and Tweddle, S. C. (1984). Weaver nest predation by an African fish eagle. The Ostrich 55, 35-36.

Verner, J., and Engelsen, G. H. (1970). Territories, multiple nest building and polygyny in the long-billed marsh wren. The Auk 87, 557-567. doi: $10.2307 / 4083798$

Welbergen, J. A. (2011). Fit females and fat polygynous males: seasonal body mass changes in the grey-headed flying fox. Oecologia 165, 629-637. doi:10.1007/s00442-010-1856-1

Withers, P. C. (1977). Energetic aspects of reproduction by the cliff swallow. The Auk 94, 718-725. doi:10.2307/4085268 